\title{
Platelet-Associated Matrix Metalloproteinases Regulate Thrombus Formation and Exert Local Collagenolytic Activity
}

Citation for published version (APA):

Mastenbroek, T. G., Feijge, M. A. H., Kremers, R. M. W., van den Bosch, M. T. J., Swieringa, F., De Groef, L., Moons, L., Bennett, C., Ghevaert, C., Johnson, J. L., van der Meijden, P. E. J., \& Cosemans, J. M. E. M. (2015). Platelet-Associated Matrix Metalloproteinases Regulate Thrombus Formation and Exert Local Collagenolytic Activity. Arteriosclerosis Thrombosis and Vascular Biology, 35(12), 2554-2561. https://doi.org/10.1161/ATVBAHA.115.306153

Document status and date:

Published: 01/12/2015

DOI:

10.1161/ATVBAHA.115.306153

Document Version:

Publisher's PDF, also known as Version of record

\section{Document license:}

Taverne

Please check the document version of this publication:

- A submitted manuscript is the version of the article upon submission and before peer-review. There can be important differences between the submitted version and the official published version of record.

People interested in the research are advised to contact the author for the final version of the publication, or visit the DOI to the publisher's website.

- The final author version and the galley proof are versions of the publication after peer review.

- The final published version features the final layout of the paper including the volume, issue and page numbers.

Link to publication

\footnotetext{
General rights rights.

- You may freely distribute the URL identifying the publication in the public portal. please follow below link for the End User Agreement:

www.umlib.nl/taverne-license

Take down policy

If you believe that this document breaches copyright please contact us at:

repository@maastrichtuniversity.nl

providing details and we will investigate your claim.
}

Copyright and moral rights for the publications made accessible in the public portal are retained by the authors and/or other copyright owners and it is a condition of accessing publications that users recognise and abide by the legal requirements associated with these

- Users may download and print one copy of any publication from the public portal for the purpose of private study or research.

- You may not further distribute the material or use it for any profit-making activity or commercial gain

If the publication is distributed under the terms of Article 25fa of the Dutch Copyright Act, indicated by the "Taverne" license above, 


\title{
Platelet-Associated Matrix Metalloproteinases Regulate Thrombus Formation and Exert Local Collagenolytic Activity
}

\author{
Tom G. Mastenbroek, Marion A.H. Feijge, Romy M.W. Kremers, Marion T.J. van den Bosch, \\ Frauke Swieringa, Lies De Groef, Lieve Moons, Cavan Bennett, Cedric Ghevaert, \\ Jason L. Johnson, Paola E.J. van der Meijden, Judith M.E.M. Cosemans
}

\begin{abstract}
Objective-Platelets are increasingly implicated in processes beyond hemostasis and thrombosis, such as vascular remodeling. Members of the matrix metalloproteinase (MMP) family not only remodel the extracellular matrix but also modulate platelet function. Here, we made a systematic comparison of the roles of MMP family members in acute thrombus formation under flow conditions and assessed platelet-dependent collagenolytic activity over time.

Approach and Results-Pharmacological inhibition of MMP-1 or MMP-2 (human) or deficiency in MMP-2 (mouse) suppressed collagen-dependent platelet activation and thrombus formation under flow, whereas MMP-9 inhibition/ deficiency stimulated these processes. The absence of MMP-3 was without effect. Interestingly, MMP-14 inhibition led to the formation of larger thrombi, which occurred independently of its capacity to activate MMP-2. Platelet thrombi exerted local collagenolytic activity capable of cleaving immobilized dye-quenched collagen and fibrillar collagen fibers within hours, with loss of the majority of the platelet adhesive properties of collagen as a consequence. This collagenolytic activity was redundantly mediated by platelet-associated MMP-1, MMP-2, MMP-9, and MMP-14 but occurred independently of platelet $\alpha$-granule release (Nbeal2 $2^{-/}$mice). The latter was in line with subcellular localization experiments, which indicated a granular distribution of MMP-1 and MMP-2 in platelets, distinct from $\alpha$-granules. Whereas MMP-9 protein could not be detected inside platelets, activated platelets did bind plasma-derived MMP-9 to their plasma membrane. Overall, platelet MMP activity was predominantly membrane-associated and influenced by platelet activation status.

Conclusions-Platelet-associated MMP-1, MMP-2, MMP-9, and MMP-14 differentially modulate acute thrombus formation and at later time points limit thrombus formation by exerting collagenolytic activity. (Arterioscler Thromb Vasc Biol. 2015;35:2554-2561. DOI: 10.1161/ATVBAHA.115.306153.)
\end{abstract}

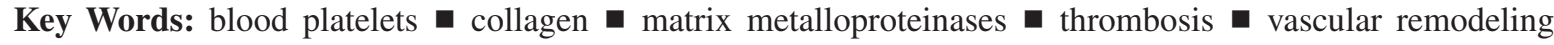

$\mathrm{I}_{\mathrm{in}}^{\mathrm{n}}$ the last decades, progress has been made in obtaining insight into the molecular mechanisms underlying platelet adhesion to exposed extracellular matrix components, subsequent platelet activation, and thrombus formation. ${ }^{1}$ It is proposed that platelet function is modulated by members of the matrix metalloproteinase (MMP) family. ${ }^{2}$ MMPs are found in most vascular and blood cells, including platelets, and in plasma. It has been demonstrated that the MMP-2 concentration in arterial blood from patients with acute coronary syndrome and in shed blood from a skin wound correlates with platelet activation and platelet number, ${ }^{3,4}$ which suggests that platelet MMPs can contribute considerably to total plasma MMP levels. Platelets contain MMP-1 (not in mouse), MMP-2,
MMP-3, and MMP-14. ${ }^{5-7}$ Over the past years, the presence of relevant levels of MMP-9 in platelets has been a matter of extensive debate. ${ }^{8-11}$ The classical view in cell biology is that MMP-14, also called membrane type 1 MMP (MT1-MMP), is membrane-inserted and that MMP-1, MMP-2, and MMP-9 become secreted on cell activation. However, there are clear indications that not only MMP-1 and MMP-2 but also MMP-9 can interact and associate with the surface of platelets. ${ }^{3,5,12-15}$ Although MMP-1 and MMP-3 seem to be mainly present in platelet $\alpha$-granules, ${ }^{16}$ conflicting evidence exists on the storage and release of platelet MMP-2 because it has been found in both the $\alpha$-granules ${ }^{16}$ and the cytoplasm. ${ }^{12}$ The recent discovery that mutations in NBEAL2 underlie an inherited

Received on: January 12, 2015; final version accepted on: September 30, 2015.

From the Department of Biochemistry (T.G.M., M.A.H.F., R.M.W.K., M.T.J.v.d.B., F.S., P.E.J.v.d.M., J.M.E.M.C.) and Synapse BV (R.M.W.K.), Cardiovascular Research Institute Maastricht (CARIM), Maastricht University, Maastricht, The Netherlands; School of Physiology and Pharmacology (M.T.J.v.d.B.) and School of Clinical Sciences (J.L.J.), University of Bristol, Bristol, United Kingdom; Neural Circuit Development and Regeneration Research Group, Department of Biology, KU Leuven, Leuven, Belgium (L.D.G., L.M.); Department of Haematology, University of Cambridge, Cambridge, United Kingdom (C.B., C.G.); and National Health Service Blood and Transplant, Cambridge Biomedical Campus, Cambridge, United Kingdom (C.B., C.G.).

The online-only Data Supplement is available with this article at http://atvb.ahajournals.org/lookup/suppl/doi:10.1161/ATVBAHA.115.306153/-/DC1. Correspondence to Judith M.E.M. Cosemans, PhD, Department of Biochemistry, Cardiovascular Research Institute Maastricht (CARIM), Maastricht University, PO Box 616, 6200 MD Maastricht, The Netherlands. E-mail judith.cosemans@ maastrichtuniversity.nl.

(C) 2015 American Heart Association, Inc. 


\begin{tabular}{|ll|}
\hline \multicolumn{2}{|c|}{ Nonstandard Abbreviations and Acronyms } \\
\hline DQ & dye quenched \\
GPVI & glycoprotein VI \\
MMP & matrix metalloproteinase \\
\hline
\end{tabular}

bleeding disorder characterized by a lack of $\alpha$-granules within platelets (gray platelet syndrome), combined with the generation of Nbeal $^{-/-}$mice, ${ }^{17}$ provides a means to investigate the subcellular localization and role of MMP family members in more detail. Most MMPs are produced in a latent pro-MMP form, which can be enzymatically activated on platelet activation. For instance, platelet MMP-14 activates MMP-2 on the platelet surface presumably by forming a complex with tissue inhibitor of metalloproteinases-2 (TIMP-2). ${ }^{5}$ Ample evidence exists that recombinant MMP-1 ${ }^{15,18}$ and MMP-2 $2^{12,13,19-21}$ potentiate adhesion or aggregation of human washed platelets or platelet-rich plasma in vitro, whereas MMP-9 exhibits an inhibitory effect. ${ }^{6,13,21,22}$ Less well studied is the role of these MMP family members in platelet activation under physiological whole blood flow conditions. To date, only for MMP-2, a role in in vivo thrombus formation has been reported. ${ }^{23} \mathrm{In}$ addition, even less is known about possible roles of MMP-3 and MMP-14 in platelet activation.

Next to their proposed effects on platelet function, MMPs are important in the physiological turnover and pathophysiological remodeling of the extracellular matrix. These vascular actions have been confined especially to the collagenase (MMP-1, MMP-8, and MMP-13) and gelatinase (MMP-2 and MMP-9) classes of MMPs that have, respectively, interstitial collagens I, II, and III and denatured collagens as major substrates. ${ }^{24}$ Although the collagenolytic activity of platelets has already been described in $1974,{ }^{25}$ it is unclear which platelet-associated MMP family members exert this activity. We hypothesize that proteolytically active MMPs associate with platelets locally at the site of injury, where they can act on both thrombus formation and underlying matrix components. For this study, a systematic comparison was made of the roles of different MMP family members on platelet activation and thrombus formation under physiological arterial flow conditions, using an established flow chamber model. ${ }^{26}$ Furthermore, platelet-collagenolytic activity was assessed over time using 3 different substrates in the presence of MMPspecific inhibitors.

\section{Materials and Methods}

Materials and Methods are available in the online-only Data Supplement.

\section{Results}

\section{Differential Modulating Effects of MMPs on Platelet Activation and Thrombus Formation Under Arterial Flow Conditions}

Human whole blood preincubated with MMP-specific inhibitors or blood from mice deficient in MMP-2, MMP-3, and MMP-9 was perfused over a fibrillar type I collagen surface at a von Willebrand factor-dependent shear rate of 1000/s to systematically compare the roles of these MMPs on platelet activation and thrombus formation. Pharmacological inhibition of MMP-1 or MMP-2 resulted in significantly diminished platelet activation and surface area covered with platelets, whereas MMP-9 or MMP-14 inhibition promoted these processes (Figure 1A and 1B). Strikingly, inhibition of the membrane-inserted MMP-14 led to the formation of fewer but larger thrombi (Figure 2), which seemed to be more stable in time (visual inspection during real-time microscopic monitoring). Interestingly, MMP-9 inhibition seemed to be without significant effect on thrombus size $(P=0.37)$, whereas platelet spreading was increased (visual inspection during real-time microscopic monitoring). No additive effect of combined MMP-9 and MMP-14 inhibition was found on thrombus size when compared with single inhibition of MMP-14 (Figure 2). This suggests that the action mechanisms by which MMP-9 and MMP-14 potentiate platelet activation and thrombus formation may differ.

Similar to the findings in human blood, the absence of MMP-2 and MMP-9 in the murine system had an opposing effect. Thrombi formed with blood from $\mathrm{Mmp2}^{-/-}$mice tended to be smaller (not shown) than wild-type thrombi and were less active as P-selectin expression (CD62P, marker for platelet secretion) and phosphatidylserine exposure (marker for platelet procoagulant activity) was significantly reduced $(P<0.05$; Figure 1C). In contrast, perfusion of blood from $M m p 9^{-/-}$mice resulted in thrombi that covered an increased surface area $(+39 \%, P=0.04)$. This was accompanied by higher levels of phosphatidylserine exposure $(+42 \%, P=0.04)$ and P-selectin expression $(+83 \%, P=0.33)$ compared with corresponding wild-type mice. Deficiency of MMP-3 had no effect on platelet activation and thrombus formation (Figure 1C), and this MMP family member was therefore not included in further experiments. Of note, the roles of MMP-1 and MMP14 could not be investigated in the murine system as MMP-1 is not expressed in murine platelets and MMP-14-deficient mice suffer from postnatal lethality. ${ }^{27}$

Based on their modulating effect on platelet activation and thrombus formation, we next investigated whether MMP-1, MMP-2, MMP-9, and MMP-14 localize on the thrombus surface. Using fluorescently labeled MMP antibodies, we found that MMP-1, MMP-2, MMP-9, and MMP-14 all associate with the membrane of a human platelet thrombus. Addition of isotype-matched control antibodies yielded no detectable levels of fluorescence (Figure 3). MMP-1, MMP-2, and MMP-9 associated with the thrombus in a speckled manner, whereas the membrane type MMP-14 seemed to be homogeneously distributed over the thrombus (Figure 3).

\section{Glycoprotein VI-Activated Platelets Rapidly Display High MMP Activity on Their Surface}

Currently, it is unclear how platelet MMP activity is triggered, as well as its relevance, compared with other sources of MMP activity. Here, we used an OmniMMP fluorogenic substrate to measure platelet-derived MMP activity (membrane bound and secreted) from washed platelets after platelet stimulation with weak (thrombin, 2-MeSADP, and thapsigargin) or strong (convulxin and ionomycin) $\mathrm{Ca}^{2+}$ mobilizing agents. ${ }^{28}$ 
A
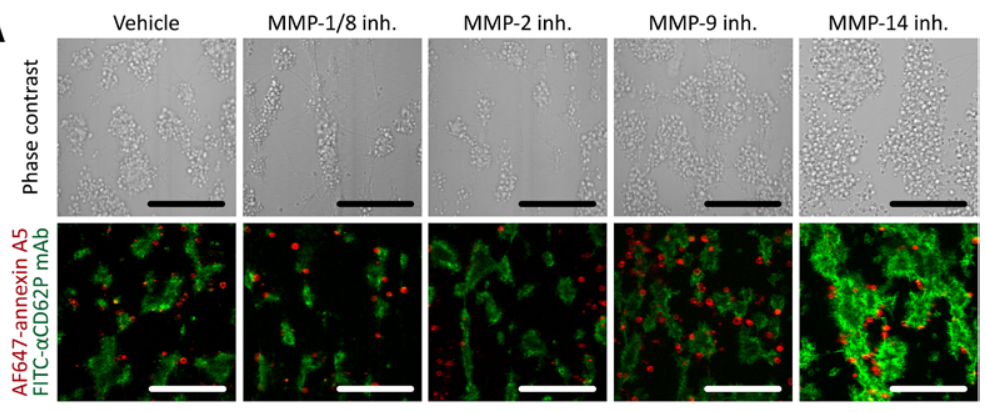

B

25070

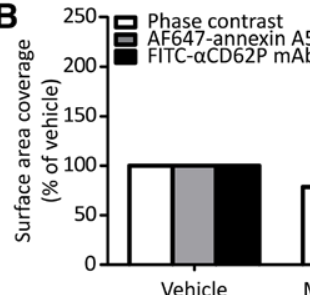
.

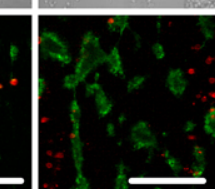

Figure 1. Matrix metalloproteinase (MMP)-1 and MMP-2 promote collagen-dependent platelet activation and thrombus formation under flow, whereas MMP-9 and MMP-14 suppress these processes. Blood from healthy human controls was preincubated with inhibitors of MMP-1/8 (FN439), MMP-2 (MMP-2 inhibitor III), MMP-9 (MMP-9 inhibitor I), and MMP-14 (NSC-405020) for 10 minutes (A and B). Alternatively, murine blood from Mmp2-, 3-, or 9-deficient mice or matched wild-types was used (C). Blood was perfused over immobilized Horm collagen at a shear rate of $1000 / \mathrm{s}$ for 4 minutes. Formed thrombi were stained for phosphatidylserine exposure and CD62P expression by postperfusion with AF647-annexin A5 and FITC-labeled $\alpha \mathrm{CD} 62 \mathrm{P}$ mAb, respectively. A, Representative phase contrast and fluorescence images of human thrombi pretreated with MMP-specific inhibitors. B, Bar graphs represent analysis of surface area coverage of human (labeled) thrombi pretreated with MMP-specific inhibitors. C, Bar graphs represent analysis of surface area coverage of (labeled) Mmp2-, 3-, or 9-deficient murine thrombi. Scale bar $=50 \mu \mathrm{m}$, data are mean \pm SEM $(n=4-7) ;{ }^{*} P<0.05$, ${ }^{\star \star} P<0.01$
Interestingly, activation with ionomycin and the glycoprotein VI (GPVI) receptor agonist convulxin (whether or not in combination with thrombin) triggered the highest levels of fluorescent MMP substrate conversion, with a 9.6-fold and 5.2-fold increase, respectively, compared with resting platelets (Figure 4A). Stimulation with the weak $\mathrm{Ca}^{2+}$-inducing agents showed a trend toward increased MMP activity, although this was not statistically significant. MMP activity was completely inhibited by the general MMP inhibitor phenanthroline (Figure 4A), but not by the cysteine, serine, and threonine protease inhibitor leupeptin $(10.7 \mu \mathrm{g} / \mathrm{mL}, \mathrm{n}=5)$, confirming selectivity of the OmniMMP assay for MMPs. A 10-fold dilution of plasma treated with 4-amino-phenyl mercuric acetate (activating latent MMPs) yielded an MMP activity of $8.5 \mu \mathrm{g} / \mathrm{mL}$ $(\mathrm{n}=7)$, which was comparable with GPVI-stimulated platelets $(9.4 \mu \mathrm{g} / \mathrm{mL})$.

Following our findings that MMP-1, MMP-2, MMP-9, and MMP-14 can associate with the thrombus surface (Figure 3) and GPVI agonists being the most potent trigger of platelet MMP activity, we next assessed the subcellular localization of these MMP family members in platelets using confocal microscopy. In resting platelets, MMP-1 and MMP-2 displayed a granular distribution, without significant overlap with the $\alpha$-granule marker P-selectin (Pearson's correlation coefficient of 0.24 for MMP-1 and 0.11 for MMP-2, Figures I and II in the online-only Data Supplement). On platelet activation with convulxin, MMP-1 and MMP-2 relocated to the platelet plasma membrane (Figure I in the online-only Data Supplement). The membrane-type MMP-14 localized on the plasma membrane of both resting and activated platelets. Interestingly, we observed caps with high levels of MMP-14 fluorescence on the plasma membrane of activated platelets, possibly suggestive of clustering of MMP activity. In line with the most recent literature, ${ }^{9,29}$ we could not detect MMP-9 in resting or activated platelets. Interestingly, activated platelets did bind plasma-derived MMP-9 within 5 minutes after their activation (Figure III in the online-only Data Supplement), which likely accounts for the MMP-9 binding to thrombi observed in Figure 3.

Given our data that activated platelets rapidly accumulate MMPs on their surface, we next measured the MMP activity of the platelet membrane fraction in comparison with the supernatant of (non)activated platelets. The vast majority of MMP activity after GPVI stimulation was indeed membrane-bound (11.3 $\mu \mathrm{g} / \mathrm{mL})$, compared with $0.5 \mu \mathrm{g} / \mathrm{mL}$ in the supernatant (Figure 4B). Kinetic experiments indicated that OmniMMP activity rapidly increased after platelet activation and reached

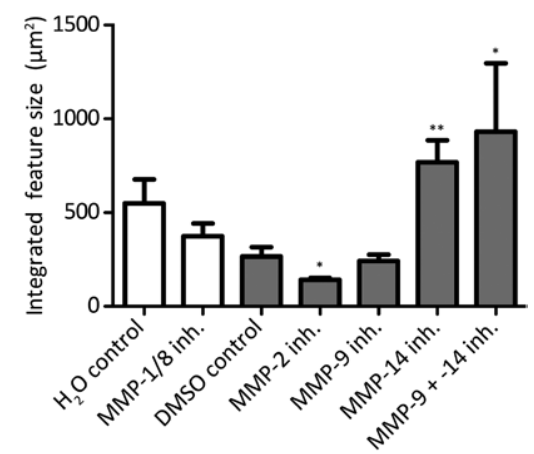

Figure 2. Inhibition of human matrix metalloproteinase (MMP) family members differentially affects thrombus size under flow. Thrombi were formed as described in Figure 1. Bar graph represents thrombus size, expressed as integrated feature size. Data are mean \pm SEM $(n=4-7) ;{ }^{*} P<0.05,{ }^{* \star} P<0.01$. 

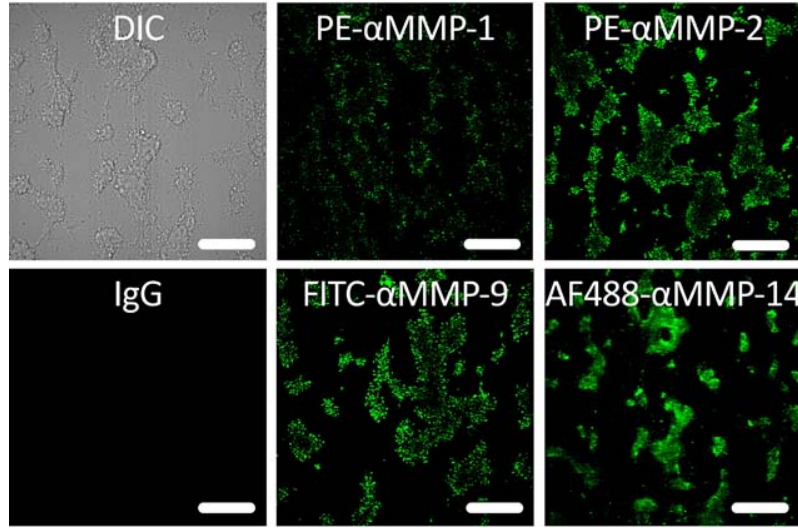

Figure 3. Human matrix metalloproteinase (MMP)-1, MMP-2, MMP-9, and MMP-14 are localized on the thrombus surface. Human blood was perfused over immobilized collagen at a shear rate of 1000/s for 4 minutes. Formed thrombi on coverslips were rinsed with HEPES buffer and poststained for MMP-1, MMP-2, and MMP-9 by single step conjugated monoclonal antibodies (mAbs). MMP-14 was stained with MMP-14 mAbs followed by AF488-conjugated secondary mAbs. Shown are a representative differential interference contrast image of formed thrombi and representative fluorescence images of MMP-1, MMP-2, MMP-9, and MMP-14 against an IgG background. Data are representative of 3 independent experiments. Scale bar $=50 \mu \mathrm{m}$. FITC indicates fluorescein isothiocyanate; and PE, phycoerythrin.

a maximum slope of $37 \mathrm{FU} / \mathrm{min} 10$ minutes after activation, after which MMP activity slowly declined (Figure 4C). Knowing that MMP-2 is reported to be activated on the platelet plasma membrane, ${ }^{5}$ we specifically measured MMP-2 activity using a cell-based MMP-2 activity assay with a reported sensitivity for MMP-2 in the nanomolar range. Platelet activation with convulxin led to a rapid increase in platelet-bound MMP-2 activity with maximal activity of $1.6 \mathrm{FU} / \mathrm{min}$ reached within 5 minutes after activation. Preincubation with MMP-2 inhibitor III completely inhibited MMP-2 activity (Figure 4D). In summary, our data suggest that platelets can rapidly display high levels of MMP activity on their membrane. This activity is dependent on platelet stimulation by strong, high cytosolic $\mathrm{Ca}^{2+}$ mobilizing agents, such as the GPVI receptor agonist convulxin.

\section{MMP-Dependent Collagen Degradation Is Localized at the Site of the Thrombus and Affected by Platelet Activation Status}

Given the presence of MMP activity on the membrane of activated platelets, we next investigated the collagen matrix degrading potential of platelet thrombi. Therefore, thrombi were formed ex vivo in a flow device on a combined surface of dye-quenched (DQ) collagen (homogeneous coating on surface) and Horm collagen (fibrillar coating) at arterial shear rate. Plasma and unbound cells were removed by careful rinsing. The absence of white blood cells was confirmed by CD45 staining (not shown). Within 1.5 hours after thrombus formation, fluorescent signals were detected because of cleavage of DQ collagen locally at the site of the thrombi, indicating collagenolytic activity, which was predominantly present at the thrombus core (Figure 5A). Similar patterns of thrombus-related fluorescence were obtained when DQ gelatin was used instead of DQ collagen (data not shown). Interestingly, on postaddition of thrombin, thrombus collagenolytic activity was predominantly detected at the thrombus shell of both human and murine thrombi (DQ collagen fluorescence pattern in Figure 5C). Collagenolytic activity was also found on the fibrillar Horm collagen fibers and platelet membrane tethers, which was most prominent after poststimulation with thrombin (representative fluorescence images, Figure 5C). Postaddition of phenanthroline immediately after the thrombi were formed led to an almost complete suppression of DQ collagen fluorescence (Figure 5A
A
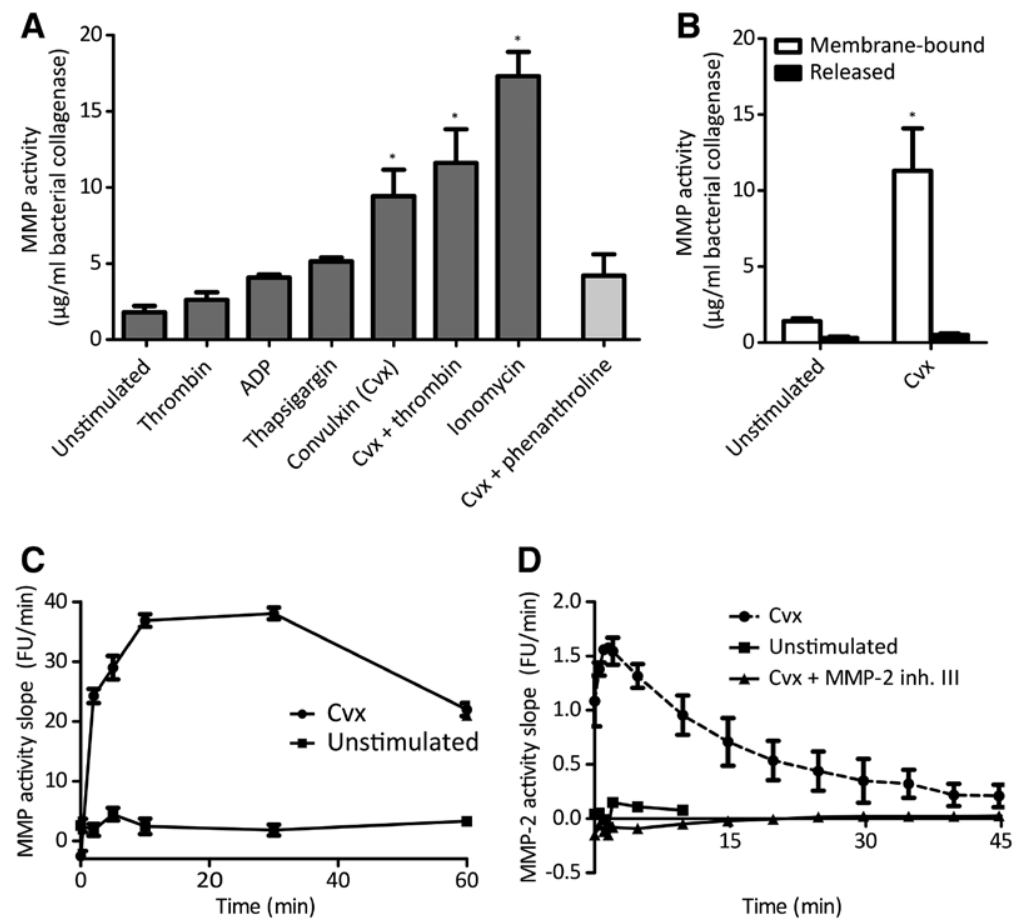

Figure 4. Platelet-derived matrix metalloproteinase (MMP) activity, which is released within minutes, is highest after glycoprotein VI (GPVI) stimulation and predominantly membrane-associated. Human resting washed platelets $\left(1 \times 10^{9} / \mathrm{mL}\right)$ were activated as indicated, and MMP activity was measured with OmniMMP substrate or selective MMP-2 EnSens substrate. A, Bar graph shows OmniMMP activity after 10 minutes stimulation of platelets with different agonists. B, Bar graph of OmniMMP activity of the membrane bound and secreted fraction of unstimulated or convulxin (Cvx)-activated platelets. C, Slope of OmniMMP activity in time (FU/min) of unstimulated and convulxin-activated platelets $(\mathrm{n}=5) ;{ }^{*} P<0.05$. D, Slope of MMP-2 activity in time (FU/min) of unstimulated and convulxin-activated platelets $(n=3)$ with(out) MMP-2 inhibitor $(n=1)$. Data are mean \pm SEM. 
A
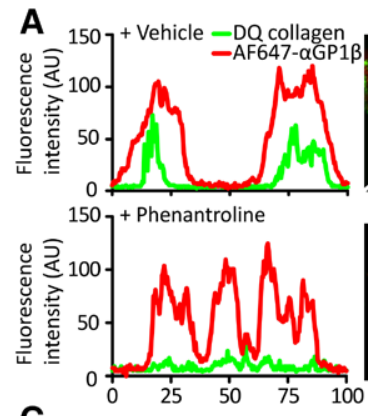

C 1507 Human, + thrombin
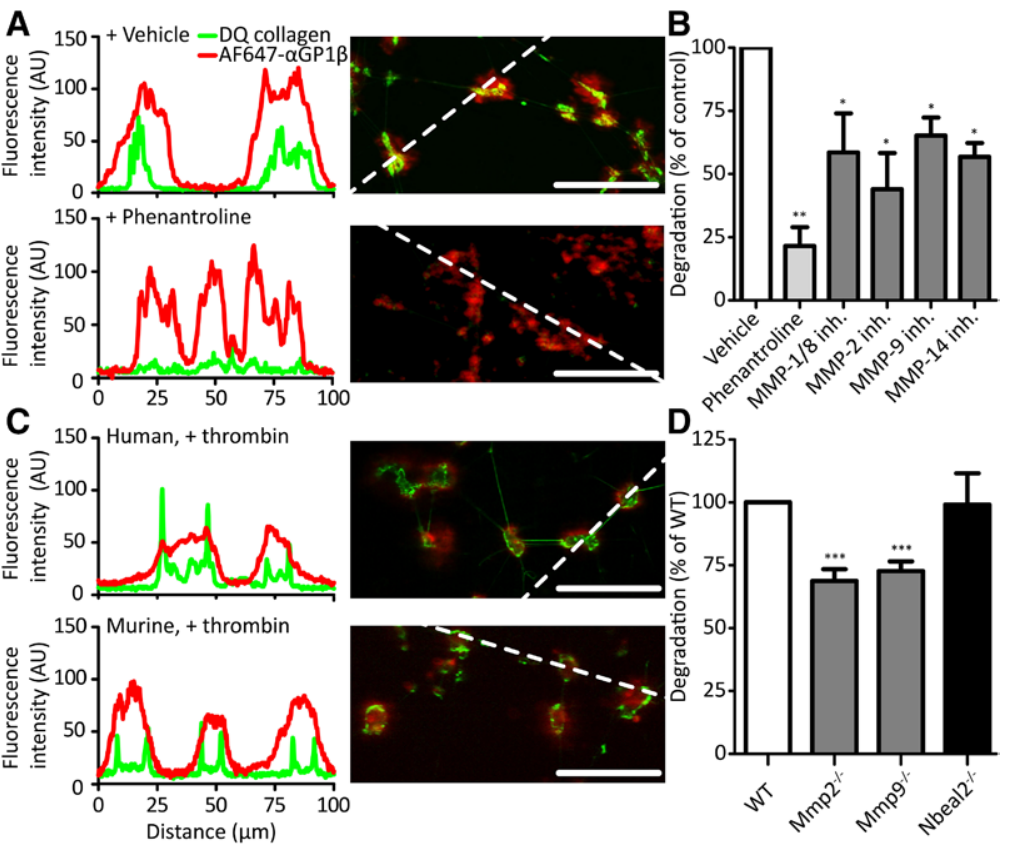

Figure 5. Matrix metalloproteinase (MMP)-dependent collagen degradation is localized at the site of the thrombus and is redundantly regulated by MMPs but not platelet $\alpha$-granule release. Human or murine blood was incubated with AF647- $\alpha$ GPIb $\alpha$ mAb to label platelets and perfused over a combined surface of immobilized Horm and dye-quenched (DQ) collagen at a shear rate of $1000 / \mathrm{s}$ for 4 minutes. Formed thrombi were postincubated with HEPES buffer containing 2-MeSADP with(out) phenanthroline or MMP-specific inhibitors. MMP activity was visualized as fluorescence signal by confocal microscopy. A and C, Representative fluorescence profiles and images taken 1.5 hours after thrombus formation. White dotted line indicates area of the fluorescence profile. B, Bar graph expresses DQ collagen fluorescence as the percentage of collagen degradation in the presence of general and selective MMP-specific inhibitors compared with corresponding vehicle controls. C, Representative fluorescence profiles and images of human and murine DQ collagen and AF647- $\alpha$ GPIb $\alpha$ taken 1.5 hours after thrombus formation in the presence of thrombin. $\mathbf{D}$, Bar graph expresses DQ collagen degradation for Mmp2-, Mmp9-, or Nbeal2-deficient murine blood or matched wild types (WT). Scale bar $=30 \mu \mathrm{m}$, data are mean \pm SEM $(\mathrm{n}=4-9) ;{ }^{\star} P<0.05,{ }^{\star \star} P<0.01,{ }^{\star \star \star} P<0.001$. and 5B). Postaddition of MMP-specific inhibitors resulted in a significant suppression of DQ collagen fluorescence of $40 \%$ to $60 \%$ depending on the inhibitor used (Figure 5B). The comparable effects found with the different MMP-specific inhibitors, suggest a redundancy in the collagenolytic capacity of platelet MMP-1, MMP-2, MMP-9, and MMP-14. A similar reduced thrombus-dependent collagenolytic activity was observed with thrombi made from wild-type, $\mathrm{Mmp}^{-/-}$or $\mathrm{Mmp}^{-{ }^{--}}$blood (Figure 5C and 5D). Interestingly, no difference was observed with $\mathrm{Nbeal2}^{-/-}$thrombi, indicating that thrombus-dependent collagenolytic activity is not mediated via $\alpha$-granule release
(Figure 5D). This fits with our data that platelet-MMPs are predominantly localized outside platelet $\alpha$-granules (Figure I in the online-only Data Supplement).

Alternatively, thrombus-dependent degradation of fibrillar type I collagen was visualized over time using scanning electron microscopy. Type I collagen fibers became visibly thinner within 3 hours of incubation with thrombi, started to fragment at 4 hours, and were nearly completely cleared after 17 hours. Adherent and spread platelets were still present at the site of the thrombus (Figure 6). This process was dependent on MMP activity as addition of phenanthroline
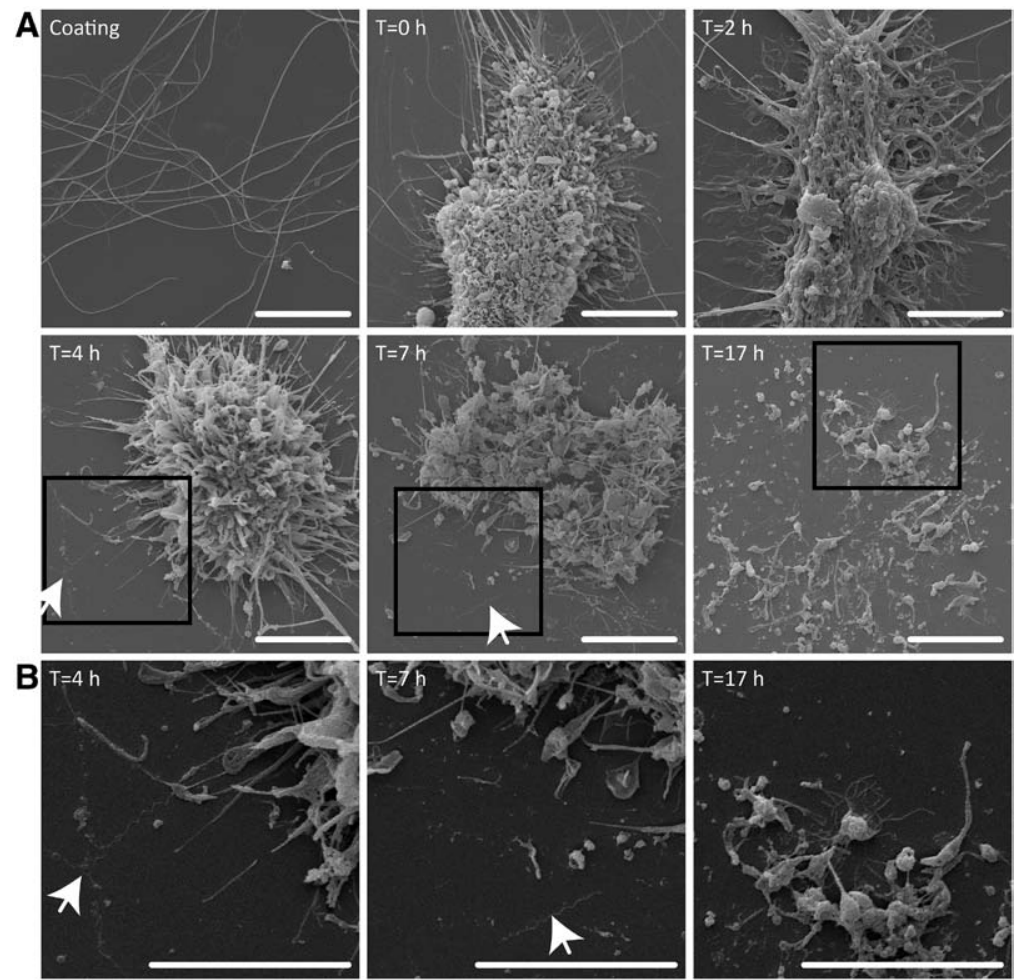

Figure 6. Thrombi degrade underlying collagen fibers in a time-dependent manner. Human whole blood was perfused over immobilized Horm collagen at a shear rate of $1000 / \mathrm{s}$ for 4 minutes. Formed thrombi were rinsed and incubated in HEPES buffer containing 2-MeSADP. At indicated time points, thrombi were fixed and prepared for SEM. A, Representative SEM pictures of Horm collagen coating before thrombus formation and of formed thrombi on collagen at $\mathrm{T}=0,2,4,7$, and 17 hours. B, Insets of indicated squares in A. Arrows indicate partly degraded collagen fibers. Representative SEM images of 9 experiments are depicted. Scale bar $=10 \mu \mathrm{m}$ 
prevented degradation of collagen by $75 \%$ (Figure IV in the online-only Data Supplement). To investigate the ability of platelet-degraded collagen to sustain platelet deposition, preformed thrombi ( $\mathrm{T}=0$ hour) were incubated with HEPES buffer supplemented with 2-MeSADP/thrombin for 6 hours and then rinsed. Freshly taken $\mathrm{DiOC}_{6}$-labeled whole blood was then flowed over the same surface for 4 minutes. Whereas initial thrombus surface area coverage was $22.2 \pm 4.5 \%(\mathrm{~T}=0$ hour), surface area covered by fresh $\mathrm{DiOC}_{6}$-labeled blood was greatly reduced to $1.5 \pm 0.7 \%(P<0.001)$, indicating a loss of platelet adhesive properties of platelet-degraded collagen (Figure V in the online-only Data Supplement). Of note, labeling with the membrane probe $\mathrm{DiOC}_{6}$ did not affect platelet adhesive capacity (not shown). In sum, these results show that platelet-associated MMP family members are capable of locally degrading an immobilized collagen matrix in a redundant manner, thereby restricting future thrombus formation in vitro.

\section{Discussion}

This study demonstrates, for the first time, that platelet-associated MMP-1, MMP-2, MMP-9, and MMP-14 play a dual role in collagen-dependent thrombus formation. They directly modulate platelet activation and thrombus formation under flow and are capable of degrading the underlying collagen matrix, thereby restricting future thrombus formation.

Using the established multiparameter flow chamber assay, ${ }^{26}$ we made a systematic comparison of the role of different MMP family members in whole blood platelet activation and thrombus formation under arterial flow conditions. Interestingly, whereas MMP-1 and MMP-2 enhance, MMP-9 and MMP-14 inhibit platelet P-selectin expression (marker for platelet secretion), platelet procoagulant activity, and thrombus formation. Deficiency in MMP-3 was without effect on these parameters, which is in line with a report that similarly found no effect of MMP-3 inhibition on platelet aggregation in the human system. ${ }^{18}$ Our results about the stimulatory function of MMP-1 and MMP-2 extend the finding that MMP-1 can bind to platelet $\beta_{3}$ thereby priming platelets for aggregation $^{18}$ and that MMP-2 is involved in the modification of platelet glycoprotein Ib-V-IX and $\alpha_{\mathrm{IIb}} \beta_{3}$ resulting in enhanced platelet adhesion and aggregation. ${ }^{14,22}$ MMP-1 has also been reported to cleave the $\mathrm{N}$-terminal exodomain of the thrombin receptor, protease-activated receptor-1, resulting in a tethered ligand that activates $G$ protein-coupled receptor pathways in platelets. ${ }^{15}$ However, this article received no follow-up in literature to date.

The thrombus inhibiting effects of MMP-9 and MMP-14 seem to be more potent than the stimulatory effects of MMP-1 and MMP-2. We propose that MMP-9 interferes with platelet adhesive properties because we observed increased platelet spreading and surface area covered by thrombi on MMP-9 inhibition, whereas thrombus size was comparable with the vehicle control. Cleavage of platelet CD40L by MMP-9 ${ }^{30,31}$ may affect thrombus stability at a later stage. ${ }^{32}$ In contrast, MMP-14 was shown to primarily limit thrombus growth and stabilization because both the surface area coverage and the thrombus size were increased in the presence of the MMP-14 inhibitor. The used pharmacological inhibitor of MMP-14 (NSC-405020) does not interfere with the capacity to activate MMP-2, ${ }^{33}$ suggesting that the other targets for MMP-14 on the platelet surface may exist. As NSC-405020 directly interacts with the hemopexin domain of MMP-14, possible targets for MMP-14 could be linked to the homodimerization of MMP14 or its collagenolytic activity. ${ }^{33}$

Our observation that MMP-1, MMP-2, MMP-9, and MMP-14 associate with thrombi formed on collagen under flow was substantiated by our finding that MMP-1 and MMP-2 rapidly relocate from granule structures inside the platelet to the plasma membrane of activated platelets. The membrane-type MMP-14 localized on the plasma membrane of both unstimulated and activated platelets. Although we could not detect MMP-9 protein in resting or activated platelets, we did observe that activated platelets bind plasmaderived MMP-9, which likely accounts for the MMP-9 binding to thrombi observed in Figure 3. Based on our findings, it is tempting to conclude that MMP-9 is most likely absent or present in neglectable amounts in platelets. However, given the persistent debate in literature on this topic, we decided to perform an extensive literature search and found 26 original research reports in which the presence of MMP-9 was examined in human, mouse, or rat platelets. Interestingly, in 11 of 26 reports, MMP-9 was detected in platelets, whereas in the other 15 reports, it remained undetectable (Table I in the online-only Data Supplement). We here summarize key underlying reasons for this discrepancy and provide several recommendations for future studies and reporting findings: (1) platelet MMP-9 levels might be below the detection limit of some of the assays used. It is therefore of importance that authors state both the detection limit of their assay and the final sample concentration; (2) buffers containing EDTA or sodium orthovanadate $\left(\mathrm{Na}_{3} \mathrm{VO}_{4}\right)$ have reported inhibitory effects on MMP activity and should be avoided when determining MMP-9 activity using zymography ${ }^{11}$; (3) potential contamination of the platelet sample with CD45 $5^{+}$leucocytes could lead to a false-positive signal as CD45 leucocytes contain considerable levels of MMP-9.9,29 Analysis of the purity of the platelet sample (eg, by flow cytometry) is thus highly recommended; (4) When detecting platelet MMP-9 levels in a plasma environment, it should be taken into account that plasma MMP-9 can bind to activated platelets (this article). In line with this finding, platelet preactivation during blood drawing and sample preparation should be minimized to avoid plasma MMP-9 binding to the platelet plasma membrane.

We demonstrate that MMPs not only accumulate on the platelet plasma membrane but also display MMP activity. Platelet MMP activity was the highest after stimulation with strong high calcium-mobilizing agents, such as the platelet collagen GPVI receptor agonist convulxin, and reached a maximal activity after 5 to 10 minutes of activation (MMP-2 and OmniMMP substrate, respectively). At first sight, our findings may challenge reports showing that platelet-derived MMP activity after collagen stimulation is mainly confined to the supernatant $^{21}$ and not the platelet-membrane fraction. ${ }^{5,15}$ However, others that demonstrated release of MMP-2 and MMP-9, simultaneously also showed the association of these MMP family 
members with the platelet surface..$^{6,13,14,18,23}$ In addition, Chesney et $\mathrm{al}^{25}$ found that collagenase exhibits its highest activity in the platelet membrane fraction, which is in line with our findings. We postulate that nonuniformity in the use of platelet agonists and in the definition of platelet supernatant may explain part of the discrepancies in literature about platelet-derived MMP activity. In our hands, agonists evoking sustained high cytosolic $\mathrm{Ca}^{2+}$ levels, such as collagen, are strong inducers of plateletexposed MMP activity. In addition, here we define supernatant as the fraction that is secreted from (non)activated platelets, that is, the platelet releasate. This differs from the study by Trivedi et al, ${ }^{15}$ in which supernatant is referred to as the lysate of centrifugated (non)activated platelet pellet. In this case, it is expected that the actual platelet releasate is lost during the procedure and is only a fraction of the actual supernatant. ${ }^{15}$

Next, we investigated a potential physiological role for platelet membrane-associated MMP activity and found that in vitro-formed thrombi effectively cleave immobilized DQ collagen or degraded fibrillar type I collagen within hours after formation. This led to a marked restriction of future thrombus formation in vitro. Hereby, our findings add to emerging knowledge on the existence and nature of persistent thrombus activities. ${ }^{34}$ Interestingly, the core of the thrombus seemed to be most active in cleaving DQ collagen. However, on postaddition of thrombin, the thrombus-mediated MMP activity was predominantly present at the outer shell of the thrombi. Plateletassociated MMP-1, MMP-2, MMP-9, and MMP-14 (human/ mouse) mediated this collagenolytic activity in a redundant manner. The absence of platelet $\alpha$-granules $\left(\right.$ Nbeal2 $\left.^{-/-}\right)$did not affect thrombus-mediated collagenolytic activity, which fits with our observation that subcellular localization of MMP-1, MMP-2, and MMP-14 does not significantly overlap with the $\alpha$-granule constituent $\mathrm{P}$-selectin. Hereby, our data shed new light on the contrasting findings reported in literature about proposed colocalization of MMP-1 and MMP-2 with $\alpha$-granules. ${ }^{12,16}$

In sum, first, we show that MMP-1 and MMP-2 stimulate platelet activation and thrombus formation under arterial flow, whereas MMP-9 and MMP-14 act inhibitory on these processes. Second, we demonstrate that the membrane fraction of collagen-stimulated platelets exerts high levels of collagenolytic activity, which leads to localized degradation of immobilized collagen fibers and restriction of future thrombus formation. Platelet-associated MMP-1, MMP-2, MMP-9, and MMP-14 have redundant roles herein.

\section{Sources of Funding}

This study was supported by research funding from the Dutch Heart Foundation (2011T6) and ZonMW MKMD (114021004), the Netherlands to J.M.E.M. Cosemans. The support was also obtained from the Dutch Landsteiner Foundation for Blood Transfusion Research (1006) to F. Swieringa.

\section{Disclosures}

None.

\section{References}

1. Versteeg HH, Heemskerk JW, Levi M, Reitsma PH. New fundamentals in hemostasis. Physiol Rev. 2013;93:327-358. doi: 10.1152/ physrev.00016.2011.
2. Seizer P, May AE. Platelets and matrix metalloproteinases. Thromb Haemost. 2013;110:903-909. doi: 10.1160/TH13-02-0113.

3. Falcinelli E, Giannini S, Boschetti E, Gresele P. Platelets release active matrix metalloproteinase-2 in vivo in humans at a site of vascular injury: lack of inhibition by aspirin. Br J Haematol. 2007;138:221-230. doi: 10.1111/j.1365-2141.2007.06632.x.

4. Gresele P, Falcinelli E, Loffredo F, Cimmino G, Corazzi T, Forte L, Guglielmini G, Momi S, Golino P. Platelets release matrix metalloproteinase- 2 in the coronary circulation of patients with acute coronary syndromes: possible role in sustained platelet activation. Eur Heart J. 2011;32:316-325. doi: 10.1093/eurheartj/ehq390.

5. Kazes I, Elalamy I, Sraer JD, Hatmi M, Nguyen G. Platelet release of trimolecular complex components MT1-MMP/TIMP2/MMP2: involvement in MMP2 activation and platelet aggregation. Blood. 2000;96:3064-3069.

6. Sheu JR, Fong TH, Liu CM, Shen MY, Chen TL, Chang Y, Lu MS, Hsiao G. Expression of matrix metalloproteinase- 9 in human platelets: regulation of platelet activation in in vitro and in vivo studies. Br J Pharmacol. 2004;143:193-201. doi: 10.1038/sj.bjp.0705917.

7. Santos-Martínez MJ, Medina C, Jurasz P, Radomski MW. Role of metalloproteinases in platelet function. Thromb Res. 2008;121:535-542. doi: 10.1016/j.thromres.2007.06.002.

8. Cecchetti L, Tolley ND, Michetti N, Bury L, Weyrich AS, Gresele P. Megakaryocytes differentially sort mRNAs for matrix metalloproteinases and their inhibitors into platelets: a mechanism for regulating synthetic events. Blood. 2011;118:1903-1911. doi: 10.1182/blood-2010-12-324517.

9. Falcinelli E, Bury L, Tolley N, Malvestiti M, Cecchetti L, Weyrich A, Gresele P. Response MMP-9 in platelets: maybe, maybe not. Blood. 2011;118:6471-6473. doi: 10.1182/blood-2011-10-379222.

10. Kälvegren H, Jönsson S, Jonasson L. Release of matrix metalloproteinases-1 and -2 , but not -9 , from activated platelets measured by enzyme-linked immunosorbent assay. Platelets. 2011;22:572-578. doi: 10.3109/09537104.2011.583300.

11. Mannello F, Medda V. Differential expression of MMP-2 and MMP-9 activity in megakaryocytes and platelets. Blood. 2011;118:6470-6471; author reply 6471-6473. doi: 10.1182/blood-2011-07-366195.

12. Sawicki G, Sanders EJ, Salas E, Wozniak M, Rodrigo J, Radomski MW. Localization and translocation of MMP-2 during aggregation of human platelets. Thromb Haemost. 1998;80:836-839.

13. Fernandez-Patron C, Martinez-Cuesta MA, Salas E, Sawicki G, Wozniak M, Radomski MW, Davidge ST. Differential regulation of platelet aggregation by matrix metalloproteinases-9 and -2. Thromb Haemost. 1999;82:1730-1735.

14. Radomski A, Stewart MW, Jurasz P, Radomski MW. Pharmacological characteristics of solid-phase von Willebrand factor in human platelets. $\mathrm{Br}$ J Pharmacol. 2001;134:1013-1020. doi: 10.1038/sj.bjp.0704345.

15. Trivedi V, Boire A, Tchernychev B, Kaneider NC, Leger AJ, O'Callaghan $\mathrm{K}$, Covic L, Kuliopulos A. Platelet matrix metalloprotease-1 mediates thrombogenesis by activating PAR 1 at a cryptic ligand site. Cell. 2009;137:332-343. doi: 10.1016/j.cell.2009.02.018.

16. Villeneuve J, Block A, Le Bousse-Kerdilès MC, Lepreux S, Nurden P, Ripoche J, Nurden AT. Tissue inhibitors of matrix metalloproteinases in platelets and megakaryocytes: a novel organization for these secreted proteins. Exp Hematol. 2009;37:849-856. doi: 10.1016/j. exphem.2009.03.009.

17. Deppermann C, Cherpokova D, Nurden P, Schulz JN, Thielmann I, Kraft P, Vogtle T, Kleinschnitz C, Dutting S, Krohne G, Eming SA, Nurden AT, Eckes B, Stoll G, Stegner D, Nieswandt B. Gray platelet syndrome and defective thrombo-inflammation in Nbeal2-deficient mice. J Clin Invest. 2013;123:3331-3342. doi: 10.1172/JCI69210.

18. Galt SW, Lindemann S, Allen L, Medd DJ, Falk JM, McIntyre TM, Prescott SM, Kraiss LW, Zimmerman GA, Weyrich AS. Outside-in signals delivered by matrix metalloproteinase-1 regulate platelet function. Circ Res. 2002;90:1093-1099. doi: 10.1161/01.RES.0000019241.12929.EB.

19. Falcinelli E, Guglielmini G, Torti M, Gresele P. Intraplatelet signaling mechanisms of the priming effect of matrix metalloproteinase-2 on platelet aggregation. J Thromb Haemost. 2005;3:2526-2535. doi: 10.1111/j.1538-7836.2005.01614.x.

20. Martinez A, Salas E, Radomski A, Radomski MW. Matrix metalloproteinase-2 in platelet adhesion to fibrinogen: interactions with nitric oxide. Med Sci Monit. 2001;7:646-651.

21. Sawicki G, Salas E, Murat J, Miszta-Lane H, Radomski MW. Release of gelatinase A during platelet activation mediates aggregation. Nature. 1997;386:616-619. doi: 10.1038/386616a0.

22. Choi WS, Jeon OH, Kim HH, Kim DS. MMP-2 regulates human platelet activation by interacting with integrin alphaIIbbeta3. J Thromb Haemost. 2008;6:517-523. doi: 10.1111/j.1538-7836.2007.02871.x. 
23. Momi S, Falcinelli E, Giannini S, Ruggeri L, Cecchetti L, Corazzi T, Libert C, Gresele P. Loss of matrix metalloproteinase 2 in platelets reduces arterial thrombosis in vivo. J Exp Med. 2009;206:2365-2379. doi: 10.1084/ jem.20090687.

24. Visse R, Nagase H. Matrix metalloproteinases and tissue inhibitors of metalloproteinases: structure, function, and biochemistry. Circ Res. 2003;92:827-839. doi: 10.1161/01.RES.0000070112.80711.3D.

25. Chesney CM, Harper E, Colman RW. Human platelet collagenase. J Clin Invest. 1974;53:1647-1654. doi: 10.1172/JCI107715.

26. de Witt SM, Swieringa F, Cavill R, et al. Identification of platelet function defects by multi-parameter assessment of thrombus formation. Nat Commun. 2014;5:4257. doi: 10.1038/ncomms5257.

27. Holmbeck K, Bianco P, Caterina J, Yamada S, Kromer M, Kuznetsov SA, Mankani M, Robey PG, Poole AR, Pidoux I, Ward JM, Birkedal-Hansen H. MT1-MMP-deficient mice develop dwarfism, osteopenia, arthritis, and connective tissue disease due to inadequate collagen turnover. Cell. 1999;99:81-92.

28. Heemskerk JW, Mattheij NJ, Cosemans JM. Platelet-based coagulation: different populations, different functions. J Thromb Haemost. 2013;11:216. doi: 10.1111 jth.12045.

29. Wrzyszcz A, Wozniak M. On the origin of matrix metalloproteinase-2 and -9 in blood platelets. Platelets. 2012;23:467-474. doi: 10.3109/09537104.2012.682103.
30. Fernández Bello I, Álvarez MT, López-Longo FJ, Arias-Salgado EG, Martín M, Jiménez-Yuste V, Rodríguez de la Rúa A, Butta NV. Platelet soluble CD40L and matrix metalloproteinase 9 activity are proinflammatory mediators in Behçet disease patients. Thromb Haemost. 2012;107:8898. doi: 10.1160/TH11-08-0556.

31. Rahman M, Roller J, Zhang S, Syk I, Menger MD, Jeppsson B, Thorlacius $\mathrm{H}$. Metalloproteinases regulate CD40L shedding from platelets and pulmonary recruitment of neutrophils in abdominal sepsis. Inflamm Res. 2012;61:571-579. doi: 10.1007/s00011-012-0446-6.

32. André P, Prasad KS, Denis CV, He M, Papalia JM, Hynes RO, Phillips DR, Wagner DD. CD40L stabilizes arterial thrombi by a beta3 integrin-dependent mechanism. Nat Med. 2002;8:247-252. doi: 10.1038/ nm0302-247.

33. Remacle AG, Golubkov VS, Shiryaev SA, Dahl R, Stebbins JL, Chernov AV, Cheltsov AV, Pellecchia M, Strongin AY. Novel MT1-MMP smallmolecule inhibitors based on insights into hemopexin domain function in tumor growth. Cancer Res. 2012;72:2339-2349. doi: 10.1158/0008-5472. CAN-11-4149.

34. Mastenbroek TG, van Geffen JP, Heemskerk JW, Cosemans JM. Acute and persistent platelet and coagulant activities in atherothrombosis. J Thromb Haemost. 2015;13 Suppl 1:S272-S280. doi: 10.1111/ jth. 12972 .

\section{Significance}

This study demonstrates, for the first time, that platelet-associated matrix metalloproteinase (MMP)-1, MMP-2, MMP-9, and MMP-14 play a dual role in collagen-dependent thrombus formation. We show that MMP-1 and MMP-2 stimulate platelet activation and thrombus formation under arterial flow, whereas MMP-9 and MMP-14 act inhibitory on these processes. In addition, we demonstrate that the membrane fraction of collagen-stimulated platelets exerts high levels of collagenolytic activity, which leads to localized degradation of immobilized collagen fibers and restriction of future thrombus formation. Platelet-associated MMP-1, MMP-2, MMP-9, and MMP-14 have redundant roles herein. We hypothesize that this localized matrix degradation could result in increased accessibility for blood cells to infiltrate into the underlying matrix. This provides a novel and highly relevant mechanism in which it can be intervened to prevent pathological matrix remodeling, thrombosis, or bleeding. 